\title{
Cytomegalovirus and Lung Transplantation
}

\author{
G. P. Westall • M. A. Paraskeva • G. I. Snell
}

Published online: 16 June 2013

(C) Springer Science+Business Media New York 2013

\begin{abstract}
Lung transplantation has greatly improved management of patients with end-stage respiratory failure. The main cause of long-term morbidity and mortality is chronic rejection as manifested by bronchiolitis obliterans syndrome (BOS), which occurs in $49 \%$ of recipients within five years of lung transplantation. Cytomegalovirus (CMV) remains the most serious opportunistic pathogen for lung transplant recipients. Although prophylaxis with antiviral drugs has much reduced CMV-associated morbidity and mortality, subclinical reactivation syndromes still affect long-term outcomes. The focus on CMV has now shifted from its direct effects, for example CMV pneumonitis, to the indirect effects, including BOS, which are currently the main obstacle to long-term improvement of lung transplantation outcomes. This review will summarize the latest evidence on the diagnosis, immunology, prophylaxis, and treatment of this commonly encountered herpes virus.
\end{abstract}

Keywords Cytomegalovirus $\cdot$ Lung transplantation .

Herpes virus · Immunosuppression · Prophylaxis ·

Polymerase chain reaction · Ganciclovir · Valganciclovir ·

Vaccine $\cdot$ Immune monitoring

\section{Introduction}

Since the first successful lung transplant 30 years ago, lung transplantation has become an established treatment for advanced lung and pulmonary vascular disease. An important early realization was that the lung allograft is at high risk of infection - especially viral infection, and in particular cytomegalovirus (CMV) [1, 2].

G. P. Westall $(\bowtie) \cdot$ M. A. Paraskeva $\cdot$ G. I. Snell

Department of Allergy, Immunology and Respiratory Medicine, Alfred Hospital and Monash University, Commercial Road, Melbourne 3004, Australia

e-mail: G.Westall@alfred.org.au
CMV is associated with a number of clinical syndromes seen in lung transplant recipients. These syndromes are usually within the lung, and obvious acute effects include pneumonitis. More importantly, indirect long-term consequences include chronic rejection (synonymous with bronchiolitis obliterans syndrome, BOS) [2, 3•, 4].

Lung transplant researchers have made great efforts to find management strategies for CMV infection and BOS. Novel studies of lung transplant CMV diagnostics, mechanistic inflammatory pathways and therapeutics are bringing about great changes to lung transplantation (and, indirectly, to all solid-organ transplantation). The purpose of this review is to update the lung transplant clinician regarding these promising advances.

\section{History}

In the 1980s and early 90s, before the availability of potent antivirals, CMV infection was observed in 54-92\% of lung transplant patients [5]. Drawing from experience of other solid-organ transplants, it was recognized that donor and recipient CMV serostatus best predicted the probability of serious post-transplant infection [6]. At that time, some lung transplant units suggested that the combination of seropositive donor and seronegative recipient led to such a high risk of CMV infection that CMV matching at the time of transplant was essential [7]. More recently, with the availability of potent antivirals, this has become much less important [1, 2, 8].

Historically, diagnosis of CMV infection was on the basis of viral culture, cytopathology, or pathology evidence $[5,7]$. During the 90s, CMV pp65 antigenemia was also used to monitor at-risk patients. Over the last decade, CMV diagnosis has been on the basis of quantitative polymerase chain reaction (PCR) viral load assay of plasma and, more recently, bronchoalveolar lavage (BAL) fluid [9-11]. These 
new sensitive and specific tests mean clinicians must decide what constitutes a clinically significant CMV load and how to respond to asymptomatic low-level-load cases [9-12].

Prophylactic and therapeutic strategies have been based on minimizing immunosuppression (where possible) and on use of CMV hyper-immune gamma globulin and ganciclovir $[5,7,12]$. Use of ganciclovir, particularly oral ganciclovir and, more recently, oral valganciclovir for prophylaxis and even for primary treatment, has proved particularly efficacious for CMV management in lung transplantation $[2,8,13]$. However, the optimum duration of therapy is still an active area of research two decades later [2, 13-15].

Over the last few years, studies have investigated the relationship between CMV disease and specific immunity [16-18] with the objective of targeting prophylaxis at "atrisk" patients, rather than subjecting all transplant recipients to the risks of antiviral therapy $[2,11,13]$. With widespread use of ganciclovir in the 90s, it became evident that CMV resistance was a concern $[19,20]$; fortunately, resistance to antivirals has not yet proved a major problem $[2,13]$.

\section{Diagnosis of CMV Infection and Disease}

Consensus definitions are important to understanding and investigating this virus [13]. CMV infection refers to any situation, irrespective of the presence of symptoms, in which there is evidence of CMV replication. CMV disease indicates CMV infection with attributable symptoms. CMV infection can be:

1. primary: a new infection acquired by a CMV-naive seronegative recipient, typically at the time of transplant;

2. reactivation: latent-CMV reactivation in a CMV seropositive recipient; or

3. re-infection: infection of a seropositive recipient with a new CMV strain [13].

Clinical syndromes associated with CMV will be discussed in more detail below, and range from asymptomatic low-level PCR positivity to clinically evident, florid viral pneumonitis $[4,15]$. It is recognized that the overall viral burden or load is a key mechanistic and diagnostic indicator of current CMV disease, and possibly also of its future progression $[9,10,15,21]$. Westall and coworkers revealed that high levels (above a threshold of 46,000 copies $\mathrm{mL}^{-1}$ ) of CMV DNA in BAL are a better predictor of the presence of histology-proved CMV infection than is detection of CMV DNA in plasma (sensitivity and specificity of $100 \%$ and $95 \%$ vs. $71 \%$ and $94 \%$ ) [15]. Riise et al. [22] described the BAL threshold value as a viral load two standard deviations above the mean for those without pneumonitis (which as such may vary across different laboratories and patient populations). Chemaly and coworkers noted a median CMV viral load of 46,678 copies $\mathrm{mL}^{-1}$ for BAL samples from patients with positive, atypical immunohistochemistry staining for CMV in lung tissue, and 1,548,827 copies $\mathrm{mL}^{-1}$ for BAL samples with positive, typical immunohistochemistry staining $(p<0.001$ compared with those without pneumonitis) [21].

A randomized study of solid-organ transplant recipients (including those receiving lung transplants) compared blood CMV DNAemia with pp65 antigenemia [23]. Antiviral treatment was instituted when levels greater than 300,000 DNA copies $\mathrm{mL}^{-1}$ blood or 100 pp65-positive leukocytes were reached. The study concluded that, compared with antigenemia, a single DNAemia cutoff significantly reduced the number of patients requiring treatment and could be safely used to guide preemptive therapy for CMV infections.

A 2009 international survey of CMV management practices for lung transplantation [11] reported that $85 \%$ of surveyed lung transplant units based CMV monitoring on a plasma CMV viral load assay (either PCR or quantitative nucleic acid amplification test), with most defining threshold values for disease. The pp65 antigenemia assay was only used by $18.6 \%$ of units. Despite the evidence cited above, the survey reports $25.4 \%$ of centers continuing to perform viral culture on BAL and only $13.6 \%$ of centers measuring CMV PCR in BAL.

Our own center favors surveillance monitoring for CMV in the lung allograft at the time of routine bronchoscopy, and the procedure followed for "at-risk" patients is:

- surveillance bronchoscopy, with transbrochial biopsy (CMV inclusion bodies) and BAL (quantitative PCR for CMV DNA), at 6, 9, 12 and 18 months post-transplant; and - plasma CMV PCR at 6, 7, 8, 9, 10, 11, 12, 15 and 18 months post-transplant; or

- testing if clinically indicated.

We rarely observe breakthrough CMV reactivation during the six-month period of valganciclovir antiviral prophylaxis and therefore do not routinely monitor for CMV during this period [24•].

\section{Clinical Syndromes and Associations}

The long-term consequences of CMV infection can be divided into direct effects of the clinical illness and end-organ injury, and indirect effects leading to long-term morbidity and mortality. As already mentioned, CMV infection (viral replication) and CMV disease (viral replication plus clinical features) are not synonymous. It is important to note that not all patients with infection develop disease. As such, the clinical syndromes of CMV range from asymptomatic viremia to $\mathrm{CMV}$ viral syndrome or tissue-invasive disease (e.g. pneumonitis). 
CMV viral syndrome describes a flu or mononucleosislike clinical disease without end-organ involvement [25], characterized by systemic symptoms including fevers, malaise, myalgias, and arthralgias. Thrombocytopenia and leucopenia can also feature. Tissue-invasive disease in lung transplant recipients most commonly presents as pneumonitis, associated with low-grade fever, shortness of breath, and a non-productive cough. Histologically, it is characterized by classic inclusion bodies on lung biopsy. Hepatitis, gastroenteritis, and colitis can also occur.

The indirect effects of CMV have been postulated to be associated with prolonged low-level viral replication and the resultant immune response. CMV has been associated with both acute and chronic rejection and with opportunistic infection $[26,27]$.

The association between CMV infection and acute cellular rejection (ACR) is reported to be mutual, with acute rejection increasing the risk of $\mathrm{CMV}$ and viral replication increasing the risk of acute rejection [28]. The mechanism responsible is believed to be activation of vascular endothelium and inflammatory cells and subsequent induction of proinflammatory cytokines, chemokines, and growth factors, which occurs in both CMV infection and acute rejection [29-31]. This process is believed to affect both development of ACR in the setting of CMV infection and reactivation of CMV in the setting of ACR. Additionally, augmentation of immunosuppression to treat ACR can lead to further amplification of CMV viral replication, with evidence suggesting that the risk of CMV infection more than doubles after administration of antilymphocyte agents [32]. Evidence from both renal and lung transplant recipients suggests that antiviral prophylaxis reduces cellular rejection $[24 \bullet, 33,34,35 \bullet \cdot]$.

There is an emerging consensus that CMV disease is associated with development of BOS after lung transplantation $[3 \cdot, 26,29]$. Snyder and coworkers reported that treated CMV pneumonitis was a risk factor for development of BOS and for reduced survival after lung transplantation [3•], and evidence of low-level viral replication (detected in BAL) within the allograft, in the absence of CMV disease, has been associated with subsequent allograft dysfunction [24•]. These analyses support other studies that have reported reduced incidence of BOS with the use of CMV prophylaxis [5, 36-38].

\section{Immunological Monitoring for CMV}

Use of immunosuppressive medication that specifically targets T-cell function is a major contributor to CMV reactivation after lung transplantation. Despite the potentially high associated morbidity and mortality from CMV disease for this patient group, studies on the precise function of CMV-specific T-cells after lung transplantation are limited [18, 39, 40].

The CMV-naïve recipient receiving a lung allograft from a CMV seropositive donor is at highest risk of CMV-related complications because of the absence of primed CMVspecific immune responses. These patients often have CMV infection, particularly after cessation of routine antiviral prophylaxis, suggesting that at this time they may not yet have acquired protective immunity against CMV [24•]. The ability to measure and time the de-novo acquisition of host $\mathrm{CMV}$-specific $\mathrm{CD} 8^{+} \mathrm{T}$-cell immunity may provide insights into why CMV reactivation is so commonly observed in these "high-risk" lung transplant recipients (LTR). CMV seropositive LTR are also at risk of CMV reactivation and/or disease. T-cell-targeted immunosuppression that controls alloreactivity also impairs host antiviral immunity, potentially resulting in CMV reactivation from the latent state. Measuring longitudinal changes to host CMV-specific immunity from the time of transplant may provide insights into why some, but not all, CMV seropositive LTR experience episodes of CMV reactivation and/or disease.

Several assays can be used to measure CMV-specific T cell responses. The QuantiFERON-CMV assay (Cellestis, Melbourne, Australia) is an in-vitro diagnostic test that uses HLA-restricted CMV epitopes to stimulate $\mathrm{CD} 8^{+} \mathrm{T}$-cells in whole blood [6]. Detection of interferon- $\gamma($ IFN- $\gamma$ ) by use of enzyme-linked immunosorbent assay (ELISA) identifies patients with $\mathrm{CMV}$-specific $\mathrm{CD} 8^{+} \mathrm{T}$-cells.

Immune monitoring of $\mathrm{CMV}$-specific T-cell responses may reveal individuals at increased risk of CMV disease after lung transplantation, and may therefore be useful in guiding CMV prophylaxis. The QuantiFERON-CMV assay is commercially available, and in a number of clinical studies had predictive value for CMV disease [18, 41]. In particular, the presence of detectable CMV immunity may reveal patients for whom antiviral prophylaxis may be safely stopped and, conversely, the absence of CMV-specific immunity at the time that antiviral prophylaxis is usually ceased may suggest that antiviral prophylaxis should be continued until CMV-specific immunity has been established. This hypothesis is currently being evaluated by a study in which, after a fixed period of antiviral prophylaxis, patients will be randomized to either standard of care (cessation of antiviral prophylaxis) or to continued antiviral prophylaxis if the need for it is determined by use of the QuantiFERONCMV assay. Those with a negative result will receive up to an additional six months of antiviral prophylaxis. The primary end-point of the study will be the incidence of CMV reactivation in the lung allograft within seven months of ceasing antiviral prophylaxis. The results of this study will help identify whether immunological monitoring for CMV can help reduce $\mathrm{CMV}$ reactivation after lung transplantation. 
Hypogammaglobulinemia is a risk factor for late CMV disease (and other infections) [42], and our unit therefore requests a measure of total $\mathrm{IgG}$ for all patients at three and 12 months post-lung transplant. Patients with documented hypogammaglobulinemia should be considered for standard IVIg replacement therapy.

\section{Vaccines}

The high incidence of CMV reactivation despite routine use of antiviral prophylaxis emphasizes the need for better strategies to control this herpes virus. Several CMV vaccines are undergoing clinical evaluation. A CMV glycoprotein B recombinant vaccine has been shown to induce neutralizing antibodies [43] and to reduce days of viremia in a study involving kidney and liver transplant recipients [44]. A vaccine containing plasmids encoding glycoprotein $\mathrm{B}$ and phosphoprotein 65 reduced days of viremia and time to viremia for patients undergoing hemopoietic stem-cell transplantation [45].

\section{Prophylaxis}

The use of antiviral prophylaxis after lung transplantation significantly reduces the incidence of CMV pneumonitis in the lung allograft, and may also reduce the incidence of BOS [37]. There have been no large randomized trials comparing prophylactic to pre-emptive antiviral strategies for reducing CMV disease-associated outcomes for lung transplantation. Most centers advocate prophylaxis over a pre-emptive approach (whereby antiviral therapy is not routinely prescribed to at-risk lung transplant recipients but rather only started on receipt of a positive CMV isolate) [11]. Prophylactic strategies have the potential added advantage of reducing the indirect effects, including acute rejection, of CMV on the lung allograft $[24 \bullet, 31]$. Although prophylactic antiviral therapy reduces the incidence of CMV reactivation and disease [46, 47], cessation of therapy is often associated with CMV reactivation [29], suggesting that prolonged prophylactic strategies may be beneficial [48]. For CMV mismatches (donor CMV seropositive, recipient CMV seronegative) 6-12 months of antiviral prophylaxis is recommended [49]. Shorter (three month) courses of prophylaxis are associated with increased CMV infection and disease [35••], and even after six months of prophylaxis over $40 \%$ of CMV-mismatched lung transplant recipients will develop CMV infection and/or disease. Likewise, a minimum of six months' prophylaxis is advised for lung transplant recipients who are CMV seropositive at the time of transplant. Weighed against this is the risk of developing CMV resistance, particularly if there is CMV reactivation whilst on ganciclovir prophylaxis, and the added cost of either prolonged or alternative antiviral therapy [50-52]. Early post-transplant prophylactic strategies initially involve intravenous ganciclovir ( $5 \mathrm{mg} \mathrm{kg}^{-1}$ twice daily), with conversion to oral valganciclovir $\left(900 \mathrm{mg} \mathrm{day}^{-1}\right.$, dose adjusted for renal function) thereafter. CMV seropositive recipients receiving CMV seropositive donor lungs are at increased risk of late CMV disease compared with those receiving CMV seronegative lungs, and may benefit from prolonged antiviral prophylaxis [53]. CMV immunoglobulin (CMV Ig) is used by many centers, although the evidence for this approach is not strong [54].

\section{Treatment}

There are different approaches to and thresholds for treating $\mathrm{CMV}$ in lung transplant recipients, ranging from only initiating therapy when CMV reactivation is associated with end-organ dysfunction to treating asymptomatic patients who have low-level subclinical CMV reactivation. Because of data revealing that any level of CMV reactivation within the lung allograft is associated with BOS, our own transplant center favors the latter approach [24•]. The treatment we prescribe is based upon the measured CMV load within the lung allograft. Severe CMV Infection is defined as one or more of:

- BAL CMV PCR >5,000 copies $\mathrm{mL}^{-1}$;

- Tissue invasion: CMV inclusion bodies in transbronchial biopsy, colon biopsy, etc;

- Clinical suspicion of end-organ damage: CMV DNAemia with either abnormal LFTs, diarrhea or unexplained bone marrow suppression; or

- CMV syndrome: fever, malaise, leukopenia, and thrombocytopenia.

Treatment for severe CMV infection is at least two weeks' IV ganciclovir, followed by three months' secondary prophylaxis with valganciclovir (450 $\mathrm{mg}$ bd). At the treating physician's discretion, CMV hyperimmune globulin is used if believed clinically indicated.

Subclinical CMV is defined as an asymptomatic patient with CMV PCR 600-5,000 in either plasma or BAL. Treatment is valganciclovir $900 \mathrm{mg}$ bd for two weeks, with no secondary prophylaxis.

Although the bioavailability of valganciclovir is excellent and it has efficacy equivalent to that of intravenous ganciclovir for treatment of CMV disease in solid-organ transplantation [36], we continue to use intravenous ganciclovir, particularly for patients with cystic fibrosis for whom systemic absorption may be impaired. Our procedure is based on measuring CMV in the lung allograft, but we also collect a contemporaneous blood sample to guide duration of 
therapy. Standard therapy is for two weeks, but is extended if CMV DNA is still detectable in the blood or if symptoms persist (especially if CMV colitis is suspected). After treatment we maintain secondary prophylaxis at a lower dose of valganciclovir ( $900 \mathrm{mg}$ od) for a further three months, on the basis that host anti-CMV immunity is at this point not sufficiently established to guarantee CMV quiescence in the absence of valganciclovir. Neutropenia is seen in up to $10 \%$ of patients receiving valganciclovir. To minimize CMV resistance, other marrow-suppressing medications (azathioprine, mycophenolate mofetil, co-trimoxazole) should be reduced before reduction of the valganciclovir dose.

\section{Ganciclovir Resistance}

Risk factors for ganciclovir resistance include: sub-optimum ganciclovir levels, prolonged therapy, and impaired host anti-CMV immunity (CMV mismatched patients) [55]. Incidence of ganciclovir resistance after solid-organ transplantation is highest for lung transplantation and, although it may manifest as asymptomatic low-level CMV reactivation, it is more often associated with significant morbidity and mortality [56]. Ganciclovir resistance is suspected when levels of CMV viremia persist despite prolonged antiviral therapy (duration 2-6 weeks). If suspected, confirmation is via genotype analysis of CMV isolates, looking primarily for the UL97 kinase (seen in $90 \%$ of cases) and UL54 DNA polymerase genes that induce resistance mutations for the routinely used ganciclovir and valganciclovir. Second-line therapy includes substitution by or addition of foscarnet. Alternatively, high-dose IV ganciclovir [57] and mTorinhibitors (everolimus, sirolimus) have some in-vitro antiCMV effects [58], and for cases of CMV resistance many centers will reduce baseline immunosuppression and convert to an mTor-inhibitor-based regimen. Newer oral antiCMV drugs include maribavir [59] and letermovir [60].

\section{Conclusions}

CMV remains the most serious opportunistic post-lungtransplant pathogen. It is associated with chronic lung allograft dysfunction as manifested by BOS, which is currently the main obstacle to long-term survival after transplantation. Five years post-transplant almost $50 \%$ of patients have developed BOS, leading to reduced quality of life and a median survival of only three years. The objective of antiviral prophylaxis is not only to prevent CMV disease but also to minimize CMV subclinical replication and thus limit its "indirect" effects on allograft function. Risk of $\mathrm{CMV}$ is individual to each patient and is related to several factors, including previous CMV exposure, level of immunosuppression and host immunity. The optimum duration of antiviral prophylaxis is currently unknown. Although longer courses of valganciclovir reduce CMV reactivation in the first year post-transplant, late CMV reactivation after cessation of antiviral prophylaxis persists. The use of CMV immune monitoring may enable bettercustomized antiviral prophylaxis which is continued until CMV-specific T-cell immunity has been established, thereby reducing the incidence of late $\mathrm{CMV}$ and, potentially, of chronic lung allograft dysfunction.

\section{Compliance with Ethics Guidelines}

Conflict of Interest G.P. Westall has served on speakers' bureaus for Roche.

M.A. Paraskeva declares no potential conflict of interest.

G.I. Snell has served on speakers' bureaus for Roche.

Human and Animal Rights and Informed Consent This article does not contain any studies with human or animal subjects performed by any of the authors.

\section{References}

Papers of particular interest, published recently, have been highlighted as:

- Of importance

•. Of major importance

1. Shah PD, McDyer JF. Viral infections in lung transplant recipients. Seminars in respiratory and critical care medicine. 2010;31(2):24354. Epub 2010/04/01.

2. Zamora MR, Davis RD, Leonard C, Committee CMVABE. Management of cytomegalovirus infection in lung transplant recipients: evidence-based recommendations. Transplantation. 2005;80(2):15763. Epub 2005/07/26.

3. - Snyder LD, Finlen-Copeland CA, Turbyfill WJ, Howell D, Willner DA, Palmer SM. Cytomegalovirus pneumonitis is a risk for bronchiolitis obliterans syndrome in lung transplantation. American journal of respiratory and critical care medicine. 2010;181(12):1391-6. Epub 2010/02/20. Refs. [3] and [24] investigate the association between BOS and both symptomatic and asymptomatic $C M V$ reactivation.

4. Westall GP, Michaelides A, Williams TJ, Snell GI, Kotsimbos TC. Bronchiolitis obliterans syndrome and early human cytomegalovirus DNAaemia dynamics after lung transplantation. Transplantation. 2003;75(12):2064-8. Epub 2003/06/28.

5. Duncan AJ, Dummer JS, Paradis IL, Dauber JH, Yousem SA, Zenati MA, et al. Cytomegalovirus infection and survival in lung transplant recipients. The Journal of heart and lung transplantation: the official publication of the International Society for Heart Transplantation. 1991;10(5 Pt 1):638-44; discussion 45-6. Epub 1991/09/01

6. Fishman JA, Emery V, Freeman R, Pascual M, Rostaing L, Schlitt $\mathrm{HJ}$, et al. Cytomegalovirus in transplantation - challenging the status quo. Clin Transplant. 2007;21(2):149-58. Epub 2007/04/12.

7. Smyth RL, Scott JP, Borysiewicz LK, Sharples LD, Stewart S, Wreghitt TG, et al. Cytomegalovirus infection in heart-lung 
transplant recipients: risk factors, clinical associations, and response to treatment. J Infect Dis. 1991;164(6):1045-50. Epub 1991/12/01.

8. Tamm M, Aboyoun CL, Chhajed PN, Rainer S, Malouf MA, Glanville AR. Treated cytomegalovirus pneumonia is not associated with bronchiolitis obliterans syndrome. Am J Respir Crit Care Med. 2004;170(10):1120-3. Epub 2004/08/07.

9. Kerschner H, Jaksch P, Karigl G, Popow-Kraupp T, Klepetko W, Puchhammer-Stockl E. Cytomegalovirus DNA load patterns developing after lung transplantation are significantly correlated with long-term patient survival. Transplantation. 2009;87(11):1720-6. Epub 2009/06/09.

10. Michaelides A, Liolios L, Glare EM, Spelman DW, Bailey MJ, Walters EH, et al. Increased human cytomegalovirus (HCMV) DNA load in peripheral blood leukocytes after lung transplantation correlates with HCMV pneumonitis. Transplantation. 2001;72(1):141-7. Epub 2001/07/27.

11. Zuk DM, Humar A, Weinkauf JG, Lien DC, Nador RG, Kumar D. An international survey of cytomegalovirus management practices in lung transplantation. Transplantation. 2010;90(6):672-6. Epub 2010/06/29

12. Maurer JR, Snell G, de Hoyos A, Kesten S, Winton T. Outcomes of lung transplantation using three different cytomegalovirus prophylactic regimens. Transplant Proc. 1993;25(1 Pt 2):1434-5. Epub 1993/02/01.

13. Snydman DR, Limaye AP, Potena L, Zamora MR. Update and review: state-of-the-art management of cytomegalovirus infection and disease following thoracic organ transplantation. Transplant Proc. 2011;43(3 Suppl):S1-17. Epub 2011/04/22.

14. Patel N, Snyder LD, Finlen-Copeland A, Palmer SM. Is prevention the best treatment? CMV after lung transplantation. American journal of transplantation : official journal of the American Society of Transplantation and the American Society of Transplant Surgeons. 2012;12(3):539-44. Epub 2011/11/11.

15. Westall GP, Michaelides A, Williams TJ, Snell GI, Kotsimbos TC. Human cytomegalovirus load in plasma and bronchoalveolar lavage fluid: a longitudinal study of lung transplant recipients. J Infect Dis. 2004;190(6):1076-83. Epub 2004/08/21.

16. Pipeling MR, John ER, Orens JB, Lechtzin N, McDyer JF. Primary cytomegalovirus phosphoprotein 65-specific CD8+ T-cell responses and T-bet levels predict immune control during early chronic infection in lung transplant recipients. J Infect Dis. 2011;204(11):1663-71. Epub 2011/10/25.

17. Walker S, Fazou C, Crough T, Holdsworth R, Kiely P, Veale M, et al. Ex vivo monitoring of human cytomegalovirus-specific CD8+ T-cell responses using QuantiFERON-CMV. Transplant infectious disease : an official journal of the Transplantation Society. 2007;9(2):165-70. Epub 2007/04/28.

18. Westall GP, Mifsud NA, Kotsimbos T. Linking CMV serostatus to episodes of CMV reactivation following lung transplantation by measuring CMV-specific CD8+ T-cell immunity. American journal of transplantation : official journal of the American Society of Transplantation and the American Society of Transplant Surgeons. 2008;8(8):1749-54. Epub 2008/06/19.

19. Kruger RM, Shannon WD, Arens MQ, Lynch JP, Storch GA, Trulock EP. The impact of ganciclovir-resistant cytomegalovirus infection after lung transplantation. Transplantation. 1999;68(9):1272-9. Epub 1999/11/26.

20. Wreghitt TG, Abel SJ, McNeil K, Parameshwar J, Stewart S, Cary $\mathrm{N}$, et al. Intravenous ganciclovir prophylaxis for cytomegalovirus in heart, heart-lung, and lung transplant recipients. Transplant International: Official Journal of the European Society for Organ Transplantation. 1999;12(4):254-60. Epub 1999/08/26.

21. Chemaly RF, Yen-Lieberman B, Castilla EA, Reilly A, Arrigain S, Farver C, et al. Correlation between viral loads of cytomegalovirus in blood and bronchoalveolar lavage specimens from lung transplant recipients determined by histology and immunohistochemistry. J Clin Microbiol. 2004;42(5):2168-72. Epub 2004/05/08.

22. Riise GC, Andersson R, Bergstrom T, Lundmark A, Nilsson FN, Olofsson S. Quantification of cytomegalovirus DNA in BAL fluid: a longitudinal study in lung transplant recipients. Chest. 2000;118(6):1653-60. Epub 2000/12/15.

23. Gerna G, Baldanti F, Torsellini M, Minoli L, Vigano M, Oggionnis $\mathrm{T}$, et al. Evaluation of cytomegalovirus DNAaemia versus pp 65antigenaemia cutoff for guiding preemptive therapy in transplant recipients: a randomized study. Antivir Ther. 2007;12(1):63-72. Epub 2007/05/17.

24. • Paraskeva M, Bailey M, Levvey BJ, Griffiths AP, Kotsimbos TC, Williams TP, et al. Cytomegalovirus replication within the lung allograft is associated with bronchiolitis obliterans syndrome. American journal of transplantation : official journal of the American Society of Transplantation and the American Society of Transplant Surgeons. 2011;11(10):2190-6. Epub 2011/07/29. Refs. [3] and [24] investigate the association between BOS and both symptomatic and asymptomatic CMV reactivation.

25. Ljungman P, Griffiths P, Paya C. Definitions of cytomegalovirus infection and disease in transplant recipients. Clinical infectious diseases: an official publication of the Infectious Diseases Society of America. 2002;34(8):1094-7. Epub 2002/03/27.

26. Duncan SR, Paradis IL, Yousem SA, Similo SL, Grgurich WF, Williams PA, et al. Sequelae of cytomegalovirus pulmonary infections in lung allograft recipients. Am Rev Respir Dis. 1992;146(6):1419 25. Epub 1992/12/01.

27. Snydman DR. Infection in solid organ transplantation. Transplant Infectious Disease: An Official Journal of the Transplantation Society. 1999;1(1):21-8. Epub 2001/06/29.

28. Tolkoff-Rubin NE, Fishman JA, Rubin RH. The bidirectional relationship between cytomegalovirus and allograft injury. Transplant Proc. 2001;33(1-2):1773-5. Epub 2001/03/27.

29. Zamora MR. Cytomegalovirus and lung transplantation. American journal of transplantation : official journal of the American Society of Transplantation and the American Society of Transplant Surgeons. 2004;4(8):1219-26. Epub 2004/07/23.

30. Weigt SS, Elashoff RM, Keane MP, Strieter RM, Gomperts BN, Xue YY, et al. Altered levels of CC chemokines during pulmonary CMV predict BOS and mortality post-lung transplantation. American journal of transplantation: official journal of the American Society of Transplantation and the American Society of Transplant Surgeons. 2008;8(7):1512-22. Epub 2008/06/03.

31. Paya CV. Indirect effects of CMV in the solid organ transplant patient. Transplant Infectious Disease: An Official Journal of the Transplantation Society. 1999;1 Suppl 1:8-12. Epub 2001/09/22.

32. Fishman JA, Rubin RH. Infection in organ-transplant recipients. $\mathrm{N}$ Engl J Med. 1998;338(24):1741-51. Epub 1998/06/12.

33. Jaksch P, Zweytick B, Kerschner H, Hoda AM, Keplinger M, Lang $\mathrm{G}$, et al. Cytomegalovirus prevention in high-risk lung transplant recipients: comparison of 3-vs 12-month valganciclovir therapy. The Journal of heart and lung transplantation : the official publication of the International Society for Heart Transplantation. 2009;28(7):670-5. Epub 2009/06/30.

34. Lowance D, Neumayer HH, Legendre CM, Squifflet JP, Kovarik J, Brennan PJ, et al. Valacyclovir for the prevention of cytomegalovirus disease after renal transplantation. International valacyclovir cytomegalovirus prophylaxis transplantation study group. N Engl J Med. 1999;340(19):1462-70. Epub 1999/05/13.

35. •- Palmer SM, Limaye AP, Banks M, Gallup D, Chapman J, Lawrence EC, et al. Extended valganciclovir prophylaxis to prevent cytomegalovirus after lung transplantation: a randomized, controlled trial. Annals of internal medicine. 2010;152(12):7619. Epub 2010/06/16. Important randomized trial demonstrating that 12 months of CMV prophylaxis is more efficacious than 3 months in reducing the incidence of $C M V$ reactivation. 
36. Asberg A, Humar A, Jardine AG, Rollag H, Pescovitz MD, Mouas $\mathrm{H}$, et al. Long-term outcomes of CMV disease treatment with valganciclovir versus IV ganciclovir in solid organ transplant recipients. American journal of transplantation: official journal of the American Society of Transplantation and the American Society of Transplant Surgeons. 2009;9(5):1205-13. Epub 2009/05/09.

37. Ruttmann E, Geltner C, Bucher B, Ulmer H, Hofer D, Hangler HB, et al. Combined CMV prophylaxis improves outcome and reduces the risk for bronchiolitis obliterans syndrome (BOS) after lung transplantation. Transplantation. 2006;81(10):1415-20. Epub 2006/05/30

38. Chmiel C, Speich R, Hofer M, Michel D, Mertens T, Weder W, et al. Ganciclovir/valganciclovir prophylaxis decreases cytomegalovirusrelated events and bronchiolitis obliterans syndrome after lung transplantation. Clinical Infectious Diseases: An Official Publication of the Infectious Diseases Society of America. 2008;46(6):831-9. Epub 2008/02/14

39. Westall G, Kotsimbos T, Brooks A. CMV-specific CD8 T-cell dynamics in the blood and the lung allograft reflect viral reactivation following lung transplantation. American journal of transplantation : official journal of the American Society of Transplantation and the American Society of Transplant Surgeons. 2006;6(3):577-84. Epub 2006/02/14.

40. Akulian JA, Pipeling MR, John ER, Orens JB, Lechtzin N, McDyer JF. High-quality CMV-specific CD4+ memory is enriched in the lung allograft and is associated with mucosal viral control. American journal of transplantation: official journal of the American Society of Transplantation and the American Society of Transplant Surgeons. 2013;13(1):146-56. Epub 2012/09/29.

41. Kumar D, Chernenko S, Moussa G, Cobos I, Manuel O, Preiksaitis J, et al. Cell-mediated immunity to predict cytomegalovirus disease in high-risk solid organ transplant recipients. American journal of transplantation: official journal of the American Society of Transplantation and the American Society of Transplant Surgeons. 2009;9(5):1214-22. Epub 2009/05/09.

42. Chambers DC, Davies B, Mathews A, Yerkovich ST, Hopkins PM. Bronchiolitis obliterans syndrome, hypogammaglobulinemia, and infectious complications of lung transplantation. The Journal of heart and lung transplantation: the official publication of the International Society for Heart Transplantation. 2013;32(1):36-43. Epub 2012/12/25.

43. Pass RF, Duliege AM, Boppana S, Sekulovich R, Percell S, Britt $\mathrm{W}$, et al. A subunit cytomegalovirus vaccine based on recombinant envelope glycoprotein B and a new adjuvant. J Infect Dis. 1999;180(4):970-5. Epub 1999/09/09.

44. Griffiths PD, Stanton A, McCarrell E, Smith C, Osman M, Harber $\mathrm{M}$, et al. Cytomegalovirus glycoprotein-B vaccine with MF59 adjuvant in transplant recipients: a phase 2 randomised placebocontrolled trial. Lancet. 2011;377(9773):1256-63. Epub 2011/04/13.

45. Kharfan-Dabaja MA, Boeckh M, Wilck MB, Langston AA, Chu $\mathrm{AH}$, Wloch $\mathrm{MK}$, et al. A novel therapeutic cytomegalovirus DNA vaccine in allogeneic haemopoietic stem-cell transplantation: a randomised, double-blind, placebo-controlled, phase 2 trial. Lancet Infect Dis. 2012;12(4):290-9. Epub 2012/01/13.

46. Razonable RR, Rivero A, Rodriguez A, Wilson J, Daniels J, Jenkins $\mathrm{G}$, et al. Allograft rejection predicts the occurrence of lateonset cytomegalovirus (CMV) disease among CMV-mismatched solid organ transplant patients receiving prophylaxis with oral ganciclovir. J Infect Dis. 2001;184(11):1461-4. Epub 2001/12/26.

47. Couchoud C. Cytomegalovirus prophylaxis with antiviral agents for solid organ transplantation. Cochrane Database Syst Rev. 2000;2, CD001320. Epub 2000/05/05.

48. Palmer SM, Grinnan DC, Diane Reams B, Steele MP, Messier RH, Duane DR. Delay of CMV infection in high-risk CMV mismatch lung transplant recipients due to prophylaxis with oral ganciclovir. Clin Transplant. 2004;18(2):179-85. Epub 2004/03/16.

49. Finlen Copeland CA, Davis WA, Snyder LD, Banks M, Avery R, Davis RD, et al. Long-term efficacy and safety of 12 months of valganciclovir prophylaxis compared with 3 months after lung transplantation: a single-center, long-term follow-up analysis from a randomized, controlled cytomegalovirus prevention trial. The Journal of heart and lung transplantation: the official publication of the International Society for Heart Transplantation. 2011;30(9):990-6. Epub 2011/04/15

50. Limaye AP, Corey L, Koelle DM, Davis CL, Boeckh M. Emergence of ganciclovir-resistant cytomegalovirus disease among recipients of solid-organ transplants. Lancet. 2000;356(9230):645-9. Epub 2000/09/01.

51. Kroes AC, Kalpoe JS. Preemptive therapy for cytomegalovirus infections and the development of resistance to ganciclovir. J Infect Dis. 2002;186(5):724-5. author reply 5-6. Epub 2002/08/27.

52. Paya C, Humar A, Dominguez E, Washburn K, Blumberg E, Alexander B, et al. Efficacy and safety of valganciclovir vs. oral ganciclovir for prevention of cytomegalovirus disease in solid organ transplant recipients. American journal of transplantation: official journal of the American Society of Transplantation and the American Society of Transplant Surgeons. 2004;4(4):611-20. Epub 2004/03/17.

53. Schoeppler KE, Lyu DM, Grazia TJ, Crossno JT, Jr., Vandervest $\mathrm{KM}$, Zamora MR. Late-onset cytomegalovirus (CMV) in lung transplant recipients: can CMV serostatus guide the duration of prophylaxis? American journal of transplantation: official journal of the American Society of Transplantation and the American Society of Transplant Surgeons. 2013;13(2):376-82. Epub 2012/12/05.

54. Weill D, Lock BJ, Wewers DL, Young KR, Zorn GL, Early L, et al. Combination prophylaxis with ganciclovir and cytomegalovirus (CMV) immune globulin after lung transplantation: effective CMV prevention following daclizumab induction. American journal of transplantation : official journal of the American Society of Transplantation and the American Society of Transplant Surgeons. 2003;3(4):492-6. Epub 2003/04/16.

55. Lurain NS, Chou S. Antiviral drug resistance of human cytomegalovirus. Clin Microbiol Rev. 2010;23(4):689-712. Epub 2010/10/12.

56. Eid AJ, Arthurs SK, Deziel PJ, Wilhelm MP, Razonable RR. Emergence of drug-resistant cytomegalovirus in the era of valganciclovir prophylaxis: therapeutic implications and outcomes. Clin Transplant. 2008;22(2):162-70. Epub 2008/03/15.

57. Gracia-Ahufinger I, Gutierrez-Aroca J, Cordero E, Vidal E, Cantisan S, Del Castillo D, et al. Use of high-dose ganciclovir for the treatment of cytomegalovirus replication in solid organ transplant patients with ganciclovir resistance-inducing mutations. Transplantation. 2013;95(8):1015-20. Epub 2013/02/15.

58. Ozaki KS, Camara NO, Nogueira E, Pereira MG, Granato C, Melaragno $\mathrm{C}$, et al. The use of sirolimus in ganciclovir-resistant cytomegalovirus infections in renal transplant recipients. Clin Transplant. 2007;21(5):675-80. Epub 2007/09/12.

59. Strasfeld L, Lee I, Tatarowicz W, Villano S, Chou S. Virologic characterization of multidrug-resistant cytomegalovirus infection in 2 transplant recipients treated with maribavir. J Infect Dis. 2010;202(1):104-8. Epub 2010/05/28.

60. Kaul DR, Stoelben S, Cober E, Ojo T, Sandusky E, Lischka P, et al. First report of successful treatment of multidrug-resistant cytomegalovirus disease with the novel anti-CMV compound AIC246. American journal of transplantation : official journal of the American Society of Transplantation and the American Society of Transplant Surgeons. 2011;11(5):1079-84. Epub 2011/04/28. 